Science, Society and the Nobel Prize

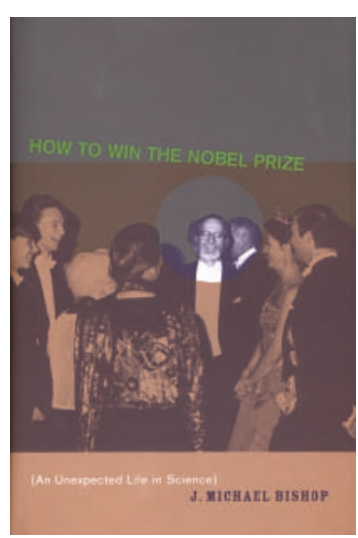

\section{How to win the Nobel Prize. An Unexpected Life in Science}

by J. Michael Bishop

Harvard University Press • 2003

$£ 18.95 / \$ 27.95$

\section{Andreas Trumpp and Daniel Kalman}

Despite the plethora of books by Nobel Laureates, none have provided us with a protocol for joining this elite group. Judging by its title, J. Michael Bishop's book "How to win the Nobel Prize" would seem to do just that. But Bishop has a larger purpose in this volume: to educate scientists and the public about science and its role in society. In the preface, Bishop argues that the general public does not understand what scientists do and who they are, and that such public misperceptions endanger the scientific enterprise. Thus, the purpose of such a provocative and facetious title appears to be to attract two distinct audiences: first, the public, who he suggests need to remain informed about the direction and scope of scientific endeavors lest their goals remain unmet and their support for science dissipate; and second, scientists themselves, who need to be aware of their responsibility to keep the public so informed as they advance science and fulfill their promise.

Bishop is a gifted communicator and teacher, and he sets about his task of educating scientists and the public by describing his career in science and science politics. He begins with a sensitive and sometimes humorous account of the events following the phone call from Stockholm. One can feel his pain in trying to schedule a press conference and simultaneously watch his beloved San Francisco Giants in the baseball playoffs. After all, winning the Nobel Prize and having the Giants reach the World Series are both rarities that need to be savoured. He also provides a marvelous description of his experiences in Stockholm, replete with royal pomp and circumstance and tales of idiosyncratic Nobelists, past and present.

The centerpiece of Bishop's book is a historical overview of infectious diseases and mankind's efforts to control them. The account begins with

Andreas Trumpp, Genetics and Stem Cell Laboratory, Swiss Institute for Experimental Cancer Research (ISREC), CH-1066 Epalinges, Switzerland. Daniel Kalman, Department of Pathology, Emory University, Atlanta, GA 30322, USA.e-mail: Andreas.Trumpp@isrec.unil.ch anddkalman@emory.edu the outbreak of bubonic plague in medieval London, and culminates with the modern scourges of AIDS and TB. Along the way, Bishop recounts efforts made by the pioneers of microbiology - Jenner, Semmelweis, Pasteur, Koch, Flemming and others - to control bacterial and viral diseases, initially by introducing hygienic practices and later with vaccines and antibiotics. This sets the stage for an introduction to cancer and the work on oncogenes for which he and Harold Varmus are so well known. Bishop describes with beautiful clarity how Peyton Rous' experiments showing that retroviruses can cause cancer, and Steve Martin's isolation of temperature-sensitive mutants in v-Src, led him and Varmus to realize that a gene could cause cancer, and to propose that the cell might itself have such a 'proto-oncogene'. In the ensuing description of the seminal experiments that provided the first validation of the proto-oncogene hypothesis, the lay reader will find the essence of who scientists are and what they do. "The pioneers in science," Bishop tells us, "are the ones who have the most fun." But Bishop is modest about his success and his motivations: "We [he and Varmus] ran no race. We did our work and it happened to lead to an amazing place." Some readers may find cause for commiseration with Bishop as he describes the reviews of his paper on the isolation of the second proto-oncogene, cMYC. While one reviewer argued that one other example would not suffice to establish the generality of the proto-oncogene hypothesis, the other one viewed the hypothesis as already established with the identification of c-Src and proclaimed Bishop's paper passé.

In the last part of the book, Bishop discusses the arena of science politics, where the relationship between science and public policy is defined. Bishop shows how his efforts, in conjunction with those of others, to educate the US Congress about science led to an increase in the NIH budget and continued support for the next generation of scientists. $\mathrm{He}$ also sets out his viewpoints on contentious issues, including, for example, research on stem cells and public science education. While some experts might debate the details of his solutions, he clearly spells out the essence of the problem for the educated public.

Throughout his narrative, Bishop provides lessons in life for the layman and scientist alike. He exhorts us to enjoy the "exhilaration of discovery, the practice of rigor, and the art of disappointment." In choosing problems, he notes that "outsiders see things more clearly than insiders" and that "convention should be ignored." He acknowledges, with some dismay, that his failure to act on his instincts cost him the discovery of reverse transcriptase but taught him a valuable lesson. An undercurrent to all these parables is his perspective of the place occupied by scientists in our society, one that he likens to that of artists, poets and musicians, but also one that he views as precarious without the public's appreciation.

Having worked with Bishop for many years as fellows in his laboratory, we find there is something entirely genuine and immediate about his account. In our experience, Bishop mentored by encouraging his junior colleagues to develop their own means of creative expression. He delineates a similar perspective in this volume, and young scientists in particular will find his account enlightening. In the end, Bishop's book provides a road map for scientists and the public to build a robust scientific community that serves our society well. In such a community, there may well be a Nobel Prize to be won. 